\title{
Influence of Building Shape on Area to Volume Ratio and Thermal Loads in Warm Climate - Case of Itahari, Nepal
}

\author{
Udvash Puri \\ Department of architecture, Acme Engineering College, \\ Purbanchal University, \\ Sitapaila, Kathmandu, Nepal
}

\begin{abstract}
Form and space are inseparable. Existence of form justifies the formation of space. Likewise, the shape also defines visual characteristics of building as well as it has a great influence on building energy demand. The thermal load of any building mostly depends upon climatic and physical parameters associated with the building itself. In this article, the comparison is done between thermal loads i.e. heating load and cooling load of hypothetical cuboid model with different $A / V$ ratios. This research aims to search relation between the exposed envelope area to $\mathrm{A} / \mathrm{V}$ ratios and their effect on energy demand. Through the findings of this research, it is expected that it could help to ease the doubt on choosing the efficient shape in this specific climate. Upon survey of households, it is found that electricity consumption in Itahari is higher in summer than in winter which is also reinforced from simulation results. This signifies the extreme need for a reduction in cooling load. Therefore, Using simulation-based correlational research strategy and inductive logic, this research indicates that a reduction in $\left(\mathrm{A}_{\text {T-Ex }} / \mathrm{V}\right)$ ratio is beneficial to reduce cooling energy demand in that given climatic and physical parameters. Findings conclude that $\left(\mathrm{A}_{\mathrm{T}-\mathrm{Ex}} / \mathrm{V}\right)$ ratio is directly proportional to energy demand in specific climatic conditions of Itahari, where $\left(\mathrm{A}_{\text {T-Ex }} / \mathrm{V}\right)$ is a total exposed envelope area including the base area of a building.
\end{abstract}

Keywords - Envelope area, simulation, A/V ratio, heating load, cooling load

\section{INTRODUCTION}

Human beings are in search of new forms for satisfying their functional and spatial needs. Human dwellings depend on structural characters and ease of available material in their surroundings [1]. Though aesthetics has been one of the important aspect of architecture for centuries, among some basic manifestation of buildings, fulfilling basic human biological needs like thermal comfort is also a prime concern.

The architectural aspects like layout orientation windows size, location, and details; shading of windows, roofs, and walls, colors, vegetation have an impact on the thermal behavior of the building [2]. Apart from that, different research indicates the shape is the most noticeable characteristic in a building that affects energy performance. Thus, the creation of form and space and defining shapes of buildings are considered as a means to solve a problem in response to functional, contextual circumstances [3].

In a global context, energy in buildings has always been an important issue. Building construction and operations accounted for the largest share of $36 \%$ in global final energy use and 39\% in energy-related CO2 emissions in 2018 [4]. In the Nepalese context, electricity consumption has grown $10.63 \%$ in 2019/20 within one year period [5]. According to Nepal electricity authority In the F/Y 2018/19, domestic consumption was the highest with $42 \%$ share.

In Nepal, the importance of energy efficiency in building sector is an immerging issue. Beside excellent vernacular architecture and climate-responsive ancient technologies, new buildings adopting modern methods of construction and new materials are unconcerned in the context of energy efficiency and passive way to achieve indoor thermal comfort. There might be numerous reasons for neglecting the energy concern in a building by designers. One of the explicit reason for skipping energy perspective in the early stage of design could be the infeasibility of time-consuming modeling for energy simulation and its technical complexities.

Therefore, this research intends to study the feasibility and role of the $\mathrm{A} / \mathrm{V}$ ratio as one of the ways that can affect the energy demand in buildings. This research is focused on comparing the heating and cooling energy demand of residential buildings in warm and slightly humid of Itahari and also the effect of building shape and configuration on them.

\section{LITERATURE REVIEW}

The modification of building shape and evolution of forms to achieve thermal comfort is a continuous process since human evolution. But according to research on historical evolution of energy-efficient building, the awareness of energy efficiency did not exist even by the end of the 19th century [6]. Furthermore, Ionescu et al. (2015), in their paper, gathered numerous moments related to energy and thermal comfort in buildings that have been fully developed till the 20th century. However, the author accepts the fact that even in ancient times either scientifically or not men discover ways to achieve thermal comfort. In this continuous process of developing new ideas, theories, a way to connect the indoor comfort and building forms lead to having understanding relation between thermal volume and balanced exposure area of building envelope. The building envelope area (A) and internal volume (V) can be connected with concept of building compactness where building compactness is a tool of 
evaluating the indoor environment performance and thermal transmission for buildings [7].

Energy efficiency in border sense can crosscut into construction, operation and demolition phase of building, however in this article reducing operational energy focuses on reducing thermal loads that have been induced by a change in building exposure area [8]. It has been mentioned in many research that building proportion has an influence in reducing or increasing thermal loads. For example, Parasonis et al. (2012) in their paper stated that building with less external envelop area but the same enclosing heated area experiences small heat loss and has effect on operational phase. From research done by Danielski, Fröling, \& Joelsson (2014), buildings with a higher shape factor have a larger surface area in proportion to their volume and have high heat losses in cold climates [9]. Since 2002 German Building Code for the energy performance of the buildings, EnergieEinsparverordnung (EnEV), has also set the requirement for the total primary energy demand of the buildings in relation to the shape factor which is basically related to exposed area and internal volume [10]. Besides these, there is numerous evidence that supports the extensive linkage of shape and thermal load. Simply, thermal loads are heating load or cooling loads which means the amount of heat energy that would need to be added to or removed from a space to maintain the temperature in an acceptable range [11]. Due to the fact that the theoretical base of building compactness is emerging, various indicators that intended to measure it in various regions [7]. Scholars suggest that there are many indicators of building compactness among which $\mathrm{A} / \mathrm{V}$ ratio is one of the indicators to link thermal load on the basis of building exposed area with reference to its internal volume. Moreover, Almumar (2016) in his article suggests that the exposed envelop area can be separated as two components of different geometrical functions; the external horizontal surfaces as roofs and lowest floors ( $A \mathrm{hs})$ and the external vertical surfaces as walls (Avs).

For simplicity, in this research the envelope area is differently categorized into an envelope with the summation of only area exposed to air (excluding base area) denoted as $\mathrm{A}_{\mathrm{S}-\mathrm{Ex}}$ and envelope with a summation of all exposed area ( including base area) denoted as $\mathrm{A}_{\mathrm{T}-\mathrm{Ex}}$. Therefore, (A/V ratio) can be calculated as $\left(\mathrm{A}_{\mathrm{T}-\mathrm{Ex}} / \mathrm{V}\right)$ and $\left(\mathrm{A}_{\mathrm{S} \text {-Ex }} / \mathrm{V}\right)$ separately. The significance of doing this is to compare the pattern of energy demand resulted through a change in different portion on exposed area. However, this article is more focused on $\mathrm{A}_{\mathrm{T} \text {-Ex }}$ $/ \mathrm{V}$ ratio due to confounded relation generated by $\mathrm{A}_{\mathrm{S}-\mathrm{Ex}} / \mathrm{V}$ ratio and Energy demand in this specific climatic condition.

\section{METHODOLOGY}

The climate files with hourly data are generated through metronome and which is then crossed verified and improvised with 10 years of climate data from the Department of Hydrology and meteorology of Nepal. The hourly radiation data are used from Energy-Plus EPW format which is converted and corrected to WEA format. On the basis of those climatic data, the numerous simulations are conducted using Ecotect analysis software and simulation results are matched with findings from online survey results. The programmed excel sheet is used to systematized the calculation of exposed area and $\mathrm{A} / \mathrm{V}$ ratios of different scenarios and are verified manually. The simulated results are then analyzed in terms of annual energy consumption and leads towards required conclusion. The brief description of the process is further discussed in research setting section of this paper.

\section{DATA SET AND RESEARCH SETTING}

The empirical environment is a composition different factors acting dynamically on a building. It will be strenuous to conclude thermal aspect of building by considering all factors like orientation, proportion of building, properties and thickness of envelope material, absorptivity and reflectivity of the opaque and transparent surface, position and size of openings, infiltration rate, operation schedule, user behavior etc. To be precise and confined with the results considering $\mathrm{A} / \mathrm{V}$ ratio as a prime factors to bring change in thermal load of building, the hypothetical cuboids with no openings are created. The findings of this research are based on controlled simulation and selective survey of houses in Aitabire area of Itahari. Simulation-based hypothetical cuboid model is conducted to get two major objectives as follows:

1. To compare the yearly heating and cooling loads of houses to achieve targeted thermal comfort range.

2. To conform to the relationship between the exposed area and $\mathrm{A} / \mathrm{V}$ ratio and its effect on heating and cooling load separately.

Four to six numbers of cuboids having a sum of total internal volume $300 \mathrm{~m}^{3}$ are arranged in a different configuration as shown in Fig. 1. For uniformity and simplicity, the horizontal as well as vertical covering of cuboids are assumed to be made up of homogeneous material (i.e. concrete) with $200 \mathrm{~mm}$ thickness. Though the internal volume remains constant, the $\mathrm{A} / \mathrm{V}$ ratio in each sample changes due to the variability of horizontal and vertical envelope area.

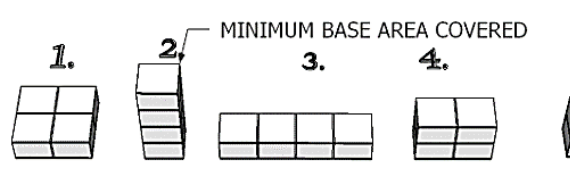

5.
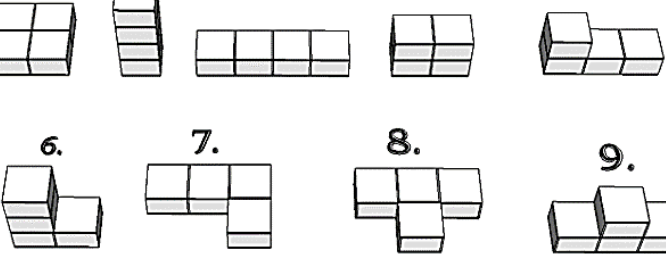

7.

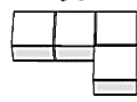

8.
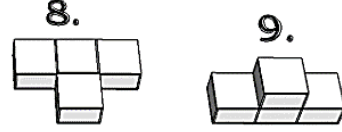
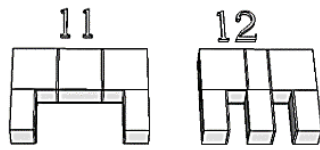

Fig. 1. Arrangement of cuboids having total internal volume $300 \mathrm{~m} 3$ but different exposed area and different $\mathrm{A} / \mathrm{v}$ ratios.

The variability in envelope area occurs due to repositioning and modification of individual cuboids. From observation, referring sample (2) as configuration covering minimum floor area as shown in Fig. 1, simulation on each sample are carried out separately. For simplicity, cuboids are 
not transformed or subtracted in sample 1 to sample 10 . However, by such a simple arrangement, the $\mathrm{A} / \mathrm{V}$ ratios obtained has an insignificant differences in their values. Therefore samples 11 and 12 are created to maximize the exposed area and obtained observable difference in ratios and energy demand. All climate consideration, U-value of material, operation schedule and assigned zonal comfort range in all zones are kept as explained in table 1.

Contemplating the climatic condition of studied site i.e. Itahari falls on the warm and slightly humid zone. The studied area is situated in eastern part of Nepal at an elevation of around $114 \mathrm{~m}$. The temperature of that reason is shown in figure 2 . The chart is created using climate consultant where a climate data area extracted through metronome. According to climate data the maximum temperature reaches up to $400 \mathrm{c}$ during peak summer and minimum temperature drops around $70 \mathrm{c}$ during winter.
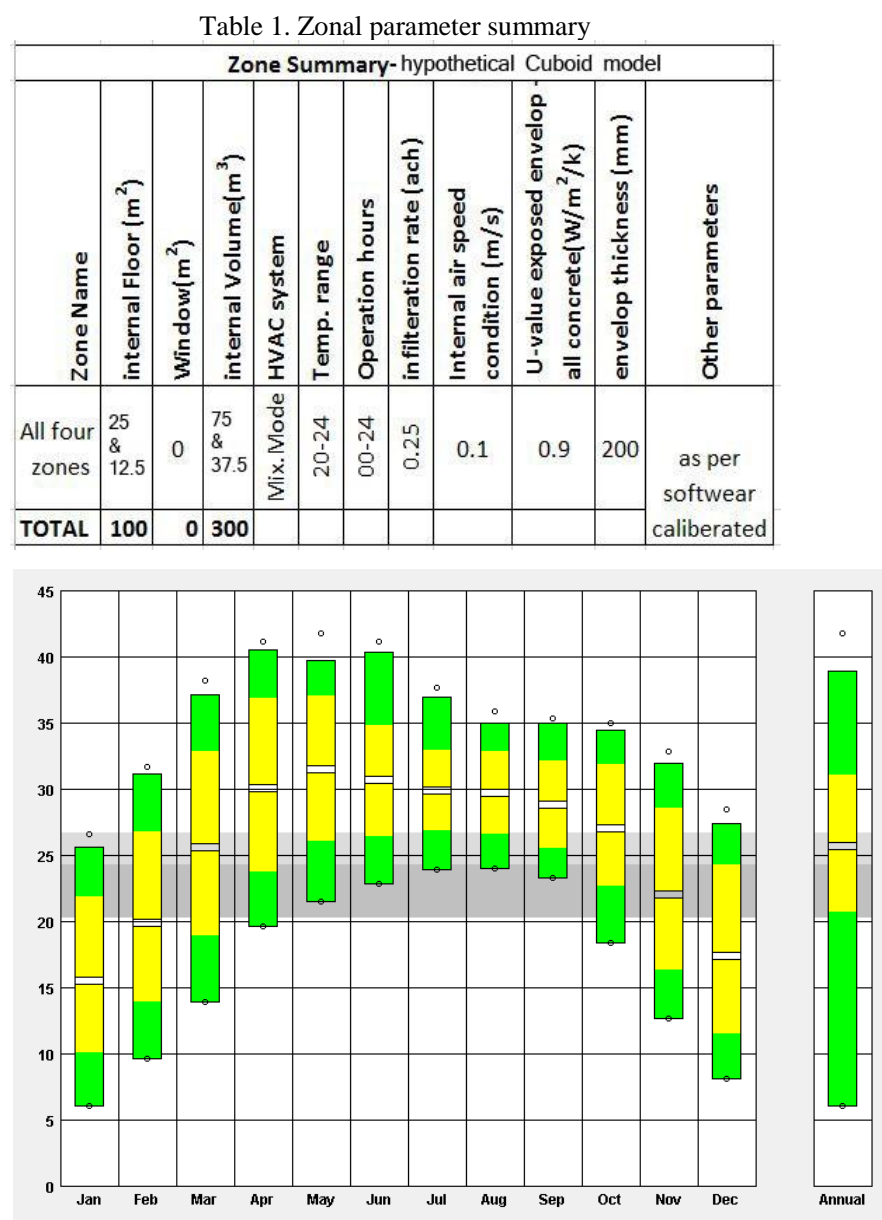

Fig. 2. Temperature data of Itahari, including summer comfort range (light grey), winter comfort range (dark grey) on the basis of ASHRAE Standard 55-2004 using PMV

\section{FINDINGS AND ANALYSIS}

\section{A. Comparison on heating and cooling demand}

As described in climatic data, the climate of Itahari is mostly warm and fairly humid most of the time of the year. The buildings tend to get heated during day and internal room temperature reaches above summer comfort range during summer months. The supply of natural air could be cost- effective way to reduce the temperature but the bioclimatic chart suggests that it would not be enough throughout the year. The evidence from preliminary climatic analysis directs the research to convince that the studied site must be cooling load dominated.

Therefore, to cross verify the climatic analysis, energy simulation and survey methods can be cost-effective and expeditious. The simulation result on comparison of average annual heating and cooling load on the 12 different samples cuboids shows that the average cooling demand in that area is $80-85 \%$ greater than average yearly heating demand as shown in Fig. 3.

To strengthen the simulation result, some of the local residential households in Aitabere area have been surveyed. The result of survey roughly supports the comparison of annual heating and cooling demand resulted through a simulation. The survey result shows that $80 \%$ of respondent have high electricity demand during summer than in winter. The household energy consumption data form a surveyed house shows that the average monthly electricity bill is $31.4 \%$ lower in the autumn season and around $40-52.3 \%$ lower in winter season in comparison to average monthly electricity bill of summer (Fig. 5). However, it is to be noted that household electricity consumption depends on many factors and uses of different electrical appliances and lighting equipment.

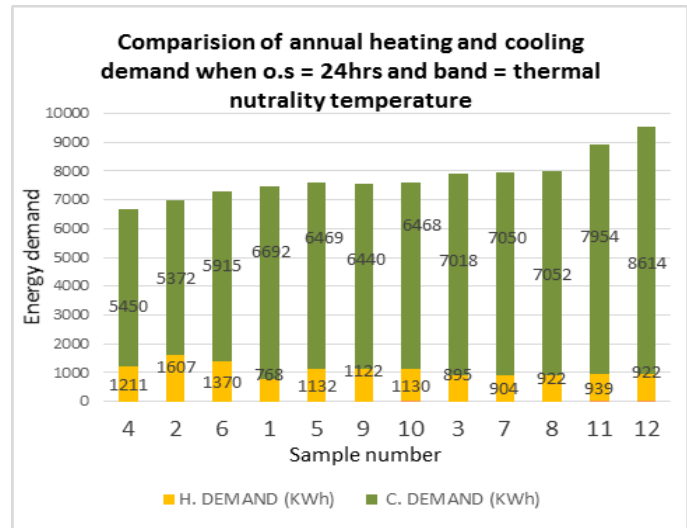

Fig. 3. Comparison of annual heating and cooling demand using simulation

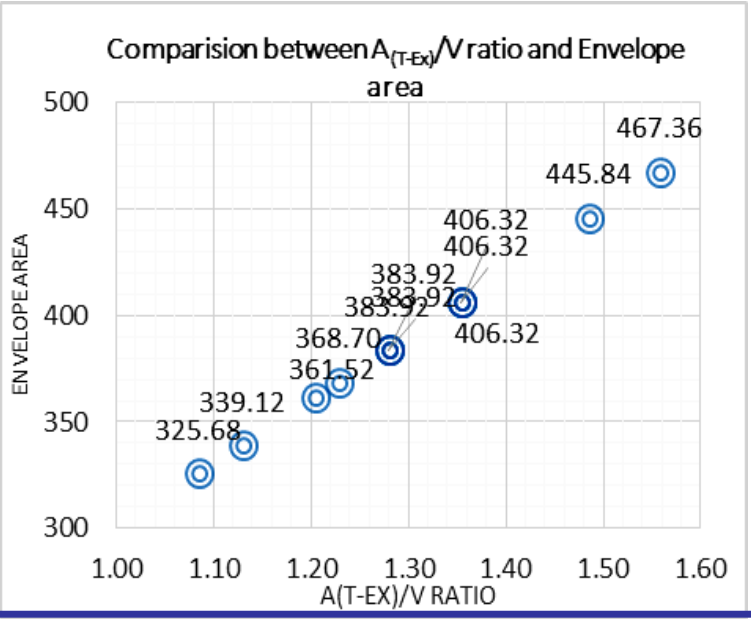


The houses surveyed have 3-8 family members on average and more than $86 \%$ respondent has answered that there is an extreme need of fan during summer whereas rest percentage use fan sometimes. In the other hand, during winter only $26.7 \%$ of respondents use a heater as an extremely needed. Whereas $40 \%$ of respondents use heater sometimes and around $34 \%$ of respondents choose need of heater as barely necessary appliances in their home. In context of indoor comfort satisfaction, the survey result suggests that more than $57 \%$ respondent feel uncomfortable during summer months, specifically during (Jestha to Sharawn) May to July and around $43 \%$ respondent feel the indoor condition is manageable most of the time by using mechanical devices.

Table 2. Result of thermal comfort survey of selected houses.

\begin{tabular}{|c|c|c|c|}
\hline & 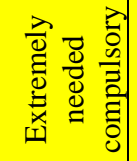 & 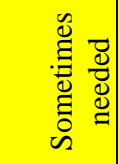 & 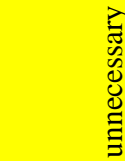 \\
\hline $\begin{array}{l}\text { Do you need Fan in } \\
\text { summer? }\end{array}$ & $86.7 \%$ & $13.3 \%$ & $0 \%$ \\
\hline \multirow[t]{2}{*}{$\begin{array}{l}\text { Do you need Heater in } \\
\text { winter? }\end{array}$} & $26.70 \%$ & $40 \%$ & $33.30 \%$ \\
\hline & 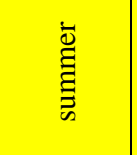 & $\stackrel{\stackrel{\grave{\Xi}}{\Xi}}{\frac{3}{3}}$ & 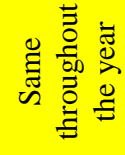 \\
\hline $\begin{array}{l}\text { Which season you feel } \\
\text { most uncomfortable? }\end{array}$ & $57.10 \%$ & $0 \%$ & $42.90 \%$ \\
\hline $\begin{array}{l}\text { Which season do you } \\
\text { have high monthly } \\
\text { electricity bill? }\end{array}$ & $80 \%$ & $6.67 \%$ & $13.33 \%$ \\
\hline
\end{tabular}

B. Findings of Simulation on Hypothetical cuboid model and Comparison between Exposure area $\left(A_{T-E x}\right)$ and $\left(A_{T-E x}\right) / V$ ratio.

The basic conclusion that can be drawn from Fig. 4 is among twelve samples that have been tested, with the increment in envelope area the $\mathrm{A} / \mathrm{V}$ ratio has increased. Needless to say, larger numeric value in numerator than in denominator gives bigger ratios. Therefore, to increase $\mathrm{A} / \mathrm{V}$ ratio the envelope area should be greater in comparison to its internal volume.

In case of a Itahari, based on the result obtained from Simulation of hypothetical cuboid model, lower the value of $\left(\mathrm{A}_{\mathrm{T}-\mathrm{Ex}} / \mathrm{V}\right)$ ratio lower is the total energy demand of the building and vice versa as shown in Fig. 6 . Thus, it will be feasible to conclude that $\left(\mathrm{A}_{\mathrm{T}-\mathrm{Ex}} / \mathrm{V}\right)$ ratio could be used to compare two different geometric forms made up of similar material for determining their total energy demand in case of Itahari.

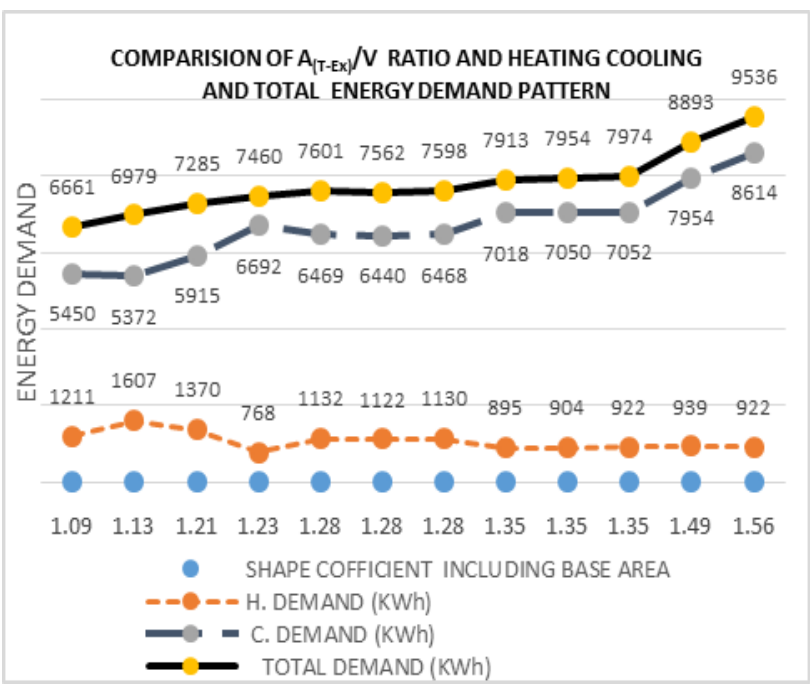

Fig. 6. Comparison of Heating, cooling and total load with $\left(\mathrm{A}_{\mathrm{T}-\mathrm{Ex}} / \mathrm{v}\right)$ ratios

In this simulation, sample (4) having a minimum (AT -Ex) /V ratio (1.09) has total annual energy demand of $6661 \mathrm{kWh}$ and sample (12) having a maximum $\mathrm{A} / \mathrm{V}$ ratio (1.56) has total annual energy demand of $9536 \mathrm{kWh}$. This means in this case a $43.5 \%$ drop in $\mathrm{A} / \mathrm{V}$ ratio leads to a 40 - $43 \%$ drop in annual energy demand. This result indicates that, under the above physical parameters, in the case of warm climatic region like Itahari $\left(\mathrm{A}_{\mathrm{T}-\mathrm{Ex}} / \mathrm{V}\right)$ ratio is proportional to total annual total energy demand. However, testing on shapes having $\left(\mathrm{A}_{\mathrm{T}-\mathrm{Ex}} / \mathrm{V}\right)$ ratio beyond the range of $(1.09-1.56)$ is also essential to amplify the accuracy of the result.

\section{DISCUSSION AND LIMITATION}

When Architects and engineers think about energyefficient and sustainable designs the pre-conceptual figures in mind are much concentrated on green material, vernacular techniques, costly energy reducing techniques, Passive technologies, energy efficient AC and so on. Therefore, this research is an effort to rethink that design of building shapes itself can be a step towards energy efficiency. This paper aims to inject $\mathrm{A} / \mathrm{V}$ ratio could also be one of the ways to reduce the energy demand but does not suggest the finding in this paper is the only ultimate way.

The A/V ratio collectively depends on both the proportion of plan as well as the vertical and horizontal exposed area concerning its thermal volume. Based on findings, for the case of Itahari, A/V ratio and annual energy demand have a proportional pattern and are related for given range. The result strongly suggests that lowering the value of the $\mathrm{A}_{\mathrm{T} \text {-Ex }} / \mathrm{V}$ ratio is a useful method to lower energy consumption. This finding could be helpful to lessen this predicament situation while choosing the right shape to some extent. Preforming energy simulation is perceived as a tedious job in the design process due to its complexity and time- consuming process. Therefore, knowing the facts that reduction or increment on $\mathrm{A} / \mathrm{V}$ ratio in a specific climate can be beneficial for energy efficiency this research could be a spark to the initial design thinking process while designing energy-efficient buildings. This research also 
widens the frame of feasibility to further study $\mathrm{A} / \mathrm{V}$ ratio in extreme climatic condition of Nepal where a higher percentage of energy demand could be reduced by modification in the shape of buildings.

Designing buildings is a diverse task. Creation has immense possibilities. Therefore, further study of $\left(\mathrm{A}_{\text {T-Ex }} / \mathrm{V}\right)$ ratio in inclined and curved forms is necessary. Moreover, this paper only discusses on right-angled shapes because most of the building has adopted these shapes from centuries but the modern era of design is adopting new forms in a building. However, the general relation from research tends to justify the conclusion. The other limitation of this study is to find actual real case experimental model having exact same internal volume but a different exposed area. The real case experimental model can be much useful to obtain a more accurate results.

\section{CONCLUSION}

From the findings, it is clear that, in case of a warm climatic condition like Itahari, buildings are cooling load dominated. In such a case, the energy efficiency of the building depends more on reducing cooling energy demand rather than focusing on heating. Therefore, it is feasible to conclude that if buildings having various shapes with similar internal volumes, constructed with a material having similar thermal properties are to be chosen for better thermal performance, then the building with a lower $\left(\mathrm{A}_{\mathrm{T} \text {-Ex }} / \mathrm{V}\right)$ ratio will be a benefit to reduce overall energy demand. Losing the heat through an envelope can be beneficial but the percentage of load reduction also depends on the operation time and functional use of buildings.

\section{REFERENCES}

[1] A. D. N. M. S. Choudhary et al., "Mathematics and Architecture: Importance of Geometry," NCAICT: National Conference on Advances in Information and Communication Technology TEQIP-II/EE/AICMT5, p. 2, 2016.

[2] B. GIVONI, "Conservation and the Use of Integrated-Passive Energy Systems in Architecture," Energy and Buildings, 3 (1981) 213 - 228, pp. $213-228,1981$.

[3] F. D. Ching, ARCHITECTURE, Form, Space, \& Order, New Jersey: John Wiley \& Sons, Inc., Hoboken, New Jersey, 2007.

[4] G. A. f. B. a. C. GlobalABC, "2019 Global Status Report for Buildings and Construction, Towards a zero-emissions, efficient and resilient buildings and construction sector," Global Alliance for Buildings and Construction (GlobalABC), United Nations, 2019.

[5] N. E. A. NEA, "A year book - Fiscal year 2018/19," NEPAL ELECTRICITY AUTHORITY, Kathmandu, 2019.

[6] C. Ionescu, T. Baracu, G.-E. vlad, H. Necula and A. Badea, "The historical evolution of the energy efficient building," Renewable and sustainable Energy reviews, pp. 243-253, 2015.

[7] M. M. S. Almumar, "Understanding Building Compactness Entity,Definition and Concept of Assessment," International Transaction Journal of Engineering, Management, \& Applied Sciences \& Technologies, 2016.

[8] J. Parasonis, A. Keizikas and D. kalibatiene, "The relationship between the shape of a building and its energy performance," Architectural Engineering and Design Management, pp. 1745-2007, 2012.

[9] B. Y. Raof, "THE CORRELATION BETWEEN BUILDING SHAPE AND BUILDING ENERGY PERFORMANCE," International journal of advanced researh (IJAR), pp. 552-561, May 2017.

[10] K. Lylykangas, "Shape Factor as an Indicator of Heating Energy Demand," 15. Internationales Holzbau-Forum 09, 2009.

[11] BASIX, "Heating and cooling loads- BASIX note help," [Online]. Available: https://basix.nsw.gov.au/iframe/thermal-help/heating-andcooling-loads. 